Unity Journal

Vol. III, 278-291, 2022

Doi:https://doi.org/10.3126/unityj.v3i01.43332

Prithvi Narayan Shah Research Center

Directorate General of Military Training, Nepali Army

Kathmandu, Nepal

\title{
Non-Traditional Security Challenges for Nepal: A Case of Covid-19
}

\section{Sambid Bilas Pant}

\section{Abstract}

The security landscape has undergone profound changes since the start of the twenty-first century. Non-Traditional Security (NTS) threats other than military, political and diplomatic conflicts have greatly impacted the lives of people. Over the years, the nature of threats and security discourses have drastically changed and countries like Nepal with low human development index have been severely affected. The coronavirus COVID-19 pandemic has brought an additional dimension to security challenges. The pandemic's impact can be felt in all aspects of life in Nepal since it is located between two South-Asian nations: China, where the outbreak was first reported and India, the second-most affected country across the world. In Nepal, COVID-19 has had an adverse impact on health, education, economy, tourism, food security, cyber security and overall development. This paper aims at critically examining the NTS approach taken by the government of Nepal and the role played by the Nepali Army (NA) to address the pandemic to ensure fundamental human rights and development. This study also aims to shed light on lessons learned from the outbreak and the future steps needed to strengthen the Global Health Diplomacy (GHD). The study is divided into four sections namely effects of covid-19, response to covid-19, overall impact at national level, suggestions and recommendations. A descriptive-analytical review of research papers, government reports, policy statements and issues papers was conducted. The paper analyzes and interprets the pandemic preparedness and response by the government and provides recommendations for strengthening health diplomacy to combat Covid-19 pandemic in Nepal.

Keywords: COVID-19, health diplomacy, non-traditional security, pandemic, South Asia

\section{Introduction}

In recent years, numerous non-military and non-traditional security (NTS) threats have replaced inter-state wars and intrastate conflicts as the main threats to national security. With changes in perceptions and emergence of new insights, NTS threats have become crucial to security discourses. There is no uncontested definition of NTS. Calballero-Anthony defines NTS threats as the issues that emerge chiefly out of nonmilitary sources and challenge the survival and well-being of people and states (NTSAsia, 2021). NTS issues such as resources insufficiency, food scarcities, infectious 
diseases, natural disasters, unbalanced migration, people trafficking, drug smuggling and international crime are often trans-national, in scope, defying unilateral remedies and requiring comprehensive socio- political, and economic -actions, as well as humanitarian use of military force (NTS-Asia, 2021) The concepts and priorities in NTS have evolved over time and it differs according to countries. Ewing \& Anthony (2021) state that while Indonesia, Singapore, and other Southeast Asian nations had given greater attention to NTS during 2000s, Japan considered human security as a key pillar of its foreign policy. In case of China, air and water pollution, pandemics, food and energy demands are recognized as security challenges to the state. In the present world, especially the western countries, the security threats of environmental degradation with implications of global climate change, demographical changes such as an aging and/ or shrinking population have emerged as the social factors that might influence global power politics in the future. However, they may still pose a credible threat to the national security of the twenty-first-century states and it is not possible to predict the possibility or consequence of a cyber-world-war (Srikanth, 2014, p.67).

According to Ong (2021), pandemic preparedness and outbreak management have been prioritized on the international stage after the outbreak of severe acute respiratory syndrome (SARS) in the year 2003. However, it took about a decade for it to become an agenda in global health governance. Amul (2021) highlights the noteworthy changes in global health governance after 2012 when non-communicable diseases (NCDs) were back in the spotlight after being consigned to the background for much of the early 2000s as the world dealt with pandemic threats; and institutional reform was a priority for the World Health Organization (WHO). Since then, the Ebola outbreak in 2014 and Zika infection in 2015 were declared by WHO to be a Public Health Emergency of International Concern (PHEIC). Although Covid-19 doesn't have the highest case fatality rate compared to other viral diseases, various factors such as a high reproduction number, superspreading events and an immunologically naive population internationally has led to the highest deaths worldwide compared to any other pandemics (Smith, 2021).

In a changing global context, combating any pandemic requires global health diplomacy. The NTS issues have been increasingly salient part of policymaking and dialogue in the Asia-Pacific region. More recently, COVID -19 has appeared as a global NTS threat and various counties have faced the challenges of different forms of NTS as a consequence. In South Asia, COVID-19 virus emerged as a NTS challenge and has had an impact on the demographics, economy, social values, political ambition and geo-politics. Recognizing the stretched economic resilience of South Asia beyond limits due to the COVID-19 outbreak, Saha and Chakrabarti (2021) indicated that South Asia's growth dropped by $7.7 \%$ in 2020 (World Bank, 2020, Cited in Saha and Chakrabarti 2021, p.112).

Asian Development Bank's Asian Development Outlook Update, 2020 further predicated that South Asia is going to be the worst hit and the economic growth of Asia as a whole will worsen. The only hope was the Indian economy which is expected to rebound by $7.7 \%$ in 2021 and the Chinese economy by $8 \%$ (BBC News, 2020, September 15, Cited in Saha and Chakrabarti 2021. P.115). In this 
regard, Saha and Chakrabarti (2021) have clearly indicated that China and India, the two leading Asian countries have to bear the responsibility of bringing economy back on track in Asia and consolidating their position in South Asia.

At a time when Nepal has faced the second wave of COVID -19 infections, various impacts have been seen in different sectors. In Nepal, COVID-19 has had an adverse impact on health due to lack of services to ordinary people who were infected by COVID -19 and those who had other critical health issues, students from early childhood to higher education were restricted from going to school and colleges, a number of people have been losing jobs in various sectors like tourism, industry and informal sectors. This article assesses COVID-19 as a NTS challenge and summarizes information regarding the effect that COVID-19 has had on various aspects of Nepal's livelihood in the past two years. Additionally, it also encapsulates the response to the pandemic in Nepal. Therefore, this article attempts to reflect on various NTS approaches that need to be taken including health diplomacy by the government of Nepal and the role played by the Nepali army (NA) to address the pandemic from the beginning of the COVID-19 In this regard, the author has used a descriptiveanalytical approach along with review of research papers, government reports, policy statements and issues papers at national and international level.

\section{Effects of COVID-19}

\section{COVID-19 and its effect on Nepal}

According to WHO updates as of 24 October 2021, A total of 809,056 (18.5\%) COVID-19 cases were confirmed through polymerase chain reaction (RT-PCR) and 4,368,512 RT-
PCR tests have been performed nationwide by designated functional COVID-19 laboratories in Nepal. A total of 94,015 $(14.6 \%)$ cases were confirmed through Antigen RDT; 644,092 Antigen RDT have been performed nationwide. It was reported that the community transmission prevailed in all provinces since 9 May 2021. Of the total RT-PCR confirmed COVID-19 cases, 97.3\% $(787,507)$ of cases have recovered, $1.3 \%$ $(10,201)$ are active cases and $11,348(1.4 \%)$ are deaths (WHO, 2021).

When COVID-19 was detected in the country on January 23, 2020, the government tried implementing preventive measures, which included the formation of the HighLevel Coordination Committee under the chairmanship of the Prime Minister and the Minister of Defense. The MOHP made various efforts to make the people aware about coronavirus. They included mobile applications (like Hamro Swasthya), call centre hotlines, and social media platforms like Facebook and Viber, among others and COVID-19 programming on TV and radio (supported by UNICEF), direct outreach through social influencers and celebrities, interviews and public/media appearances by MoHP/DoHS officials on national and local media, and daily media briefings (MOHP, 2021, p.xvi). Despite various measures taken by the government for COVID-19 prevention and care, there were number of flaws and faults in the government's action, particularly in the beginning of the pandemic. The government could not establish laboratories and prepare enough isolation and quarantine sites. It was also unable to increase public confidence in its health system (MOHP, 2021, p.xxiii).

The local government could not prepare themselves to handle the worst-case scenario and the allocation of budget was 
not adequate to cope with the COVID-19 during second wave of infections. The testing capacity could not be expanded to the vulnerable population and there was lack of a comprehensive reporting and communication system. Similarly, the government could not collaborate with the private sector, industries and businesses to produce PPE, masks, and medical equipment, among others items to provide services and increase access. (MOHP, 2021, p.xxiii

\section{Effect on women, elderly and disabled}

The COVID-19 crisis has caused mayhem around the world. It has negatively impacted vulnerable groups like pregnant women, elderly, disabled etc. The pandemic has caused interruption of healthcare service delivery worldwide, including Maternal Healthcare Services (MHS). (Pant, et al., 2021) Different methods applied to contain the COVID-19 infection (like the lockdown and movement restriction) have led to an exacerbation of the delays in: deciding to seek help, reaching healthcare center and getting access to MHS. (Pant, et al., 2021) Estimates indicate that morbidity and mortality among mothers and children may rise as a result of the delays. (Pant, et al., 2021).

Similarly, the COVID crisis has also negatively impacted the elderly. Evidence shows that elderly have increased chances of contracting severe illness due to COVID-19 and even death (Pant \& Subedi, 2020) This may be due to reduced immunity, pre-existing disease conditions, and lack of appropriate management. (Pant \& Subedi, 2020) They also have to deal with social isolation, which negatively impacts their physical and mental health. (Pant \& Subedi, 2020) Additionally, they may have to suffer financial crises due to lack of a steady source of income, insufficient savings and delays in getting pensions and social security facilities. (Pant \& Subedi, 2020)

The pandemic has uncovered breaches in the health system that has led to maltreatment and abandonment of poor, marginalized and disabled people. (Pant, et al., 2021) It has generated numerous challenges for people with disabilities (PWD). Firstly, they have higher chances of getting infected with COVD-19. (Pant, et al., 2021) Additionally, they also have trouble accessing health services and had various social problems like loss of jobs, difficulty during virtual classroom setting etc. (Pant, et al., 2021)

\section{Impact of COVID-19 on national economy and food security}

Due to the lockdown and resultant job losses, thousands of Nepali migrant workers especially those working in India were largely affected. Nepalis faced several migration related challenges particularly the crossborder migrant workers (other than India), migrant workers in India and Internal migrant workers (ILO, 2020, p. 2-4). Cross-border migrant workers in Qatar, Malaysia, Saudi Arabia, the United Arab Emirates (UAE) and Kuwait have made significant contribution with volume of remittance contributing to GDP and Nepal's economy will be severally affected as they were likely to return to Nepal due to job losses (ILO, 2020, p. 1-2).

Thousands of Nepali migrant workers residing in India for employment travelled long distances in the hope of returning to Nepal, but they were compelled to stay in the NepalIndia border due to lack of transportation without adequate food or shelter. Similarly, millions of internal migrants in Nepal, including women, daily wages workers and those working on temporary contract and 
other informal sector have been severely affected by the lockdown in the absence of sustainable wages, job guarantee, insurance and inclusion in other social security and protection mechanisms (ILO, 2020, p. 3).

The survey conducted by WFP in December 2020 in all 7 provinces revealed that Karnali and Sudurpaschim provinces were the most food insecure provinces of the country, having 24.1 and 21.2 percent of households consuming inadequate diet respectively (WFP, 2020, p. 5). The survey revealed that food security was negatively affected by job loss and income reduction caused by the COVID-19 leading to inadequate food consumption and food insufficiency (WFP, 2020, p. 6). Since the impact of the COVID-19 crisis on job loss and income reduction remains notable and can further put pressure on income generation and livelihoods, the government should take effective measures to create jobs and provide humanitarian support to combat food deficit.

\section{Cyber security}

During the lockdown, cyber criminals tried to gain access to personal information and caused phishing attack using the internet. Therefore, the government must be cautious in controlling cybercrimes especially, during the pandemic. The cyber criminals sent messages to internet users through email, WhatsApp, Viber to gain access to personal information, passwords and money (The Rising Nepal, May 11, 2021). Therefore, everyone needs to be more cautious about it and the government should be creating widespread awareness about it.

\section{Impact on tourism and transportation sector}

Due to the lockdown, every sector related to mobility e.g., the mobility of passengers and cargo (international and domestic) remained the hardest hit due to the COVID-19 pandemic which affected revenue generation in the aviation industry of Nepal. A study by (Singh $\&$ Sahi, 2021) revealed that the overall Gross Domestic Product (GDP) that the transport and its inter-linked sector contribute has been reduced considerably during the lockdown than the preceding years. Civil Aviation Authority of Nepal (CAAN) had to bear a loss of 8.33 billion in revenue collection (Singh \& Sahi, 2021)

\section{Impact of COVID-19 pandemic in education sector}

Most of the community school children who were from remote areas with poor economic background had no access to education as they did not have access to radio, TV, landline and mobiles phones (Dawadi, Giri, \& Simkhada, 2020, p.12) The Centre for Education and Human Resource Development (CEHRD) under the Ministry of Education Science and Culture made various efforts to address the needs of school children during the surge of COVID-19 in Nepal. The implementation of planned activities and the popular 'welcome to school program' for FY 2019/20 was brought to an abrupt halt in March and the SEE exam was postponed and later the students were evaluated based on the schools' evaluation sheet due to COVID-19 (CEHRD, 2019/20, p.47). All three tiers of governments were supported by various $\mathrm{I} / \mathrm{NGOs}$ in responding to COVID-19 pandemic period of 2020. The government made various efforts to facilitate students learning, facilitation through alternative modes like home-based learning/home schooling, self-learning materials distribution, and radio schooling (CEHRD,2020, p.119-120). 
Various self-learning materials and radio lessons based on grade wise curriculum were developed by CEHRD in support of the INGOs. As an effective media tool to reach the children throughout the nation, the radio learning activity, was implemented (CEHRD, 2019/20, p.119-120). In 2019/20, considering COVID-19 and other possible unforeseen disasters, contingency plan was developed and implemented in coordination, collaboration and resource sharing from different government and non-governmental agencies CEHRD, ASIP/AWPB 2020/21 p.26). Moreover, the budget allocation was hugely affected due to the global pandemic of covid-19. (CEHRD,2020, p.21).

Following the WHO declaration of COVID-19, as a pandemic, Nepal government prepared an Education Cluster Contingency Plan, 2020 and Nepal Education Cluster on 11 March 2020 (CEHRD, 2020. p.1). As reported by CEHRD, there were only $13 \%$ of schools with facilities to access the internet in $2019 / 20$ ), $55 \%$ of households with internet in their households and $51 \%$ of students could access media such as radio and TV (MICS, 2020, cited in CEHRD, 2020, p.2). Overall, it was estimated that remaining $45 \%$ students were unlikely to get regularly access to online or other media. (CEHRD,2020. p.1)

The government made commitment for implementing alternative learning model categorizing children into seven groups:

- Students who have access to all services,

- Students who have access to internet,

- Students who have access to computer or mobile phones but no (regular/stable) access to internet,

- Students who have access to mobile phones (non-smart phones),

- Students who have access to TV and/or radio and

- Students who do not have access to any of the above-mentioned media and.

- Students that have additional needs (CEHRD, 2020)

Online teacher training provision has been made to address the present situation. However, the students who did not have access to any of the ICT related materials were largely affected.

To ensure continuation of learning during the time when the schools are closed, the government developed the Guidelines on Facilitating Students' Learning and School Reopening Framework in May 2020 to facilitate learning through an alternative education system support in an effective and systematic manner to resume the learning system disrupted by the COVID-19 infections (CEHRD, 2021, p.95)

Similarly, CEHRD developed the November 2020; School Reopening Framework in November 2020; with the support from UNICEF, UNESCO and WFP for the local level for actions needed to be adopted at the school level before-, during- and after the reopening of schools by for the local level (CEHRD, 2021, p.95)

The third plan was COVID-19 Education sector Emergency Action Plan 2077 developed in February 2021. Despite these attempts towards facilitating learning during Covid-19 pandemic, there were constraints and challenges such as developing, printing and distributing child-friendly learning materials to the needy students and building the capacity of the teachers for use using 
digital and remote teaching materials and to increase their awareness on the transmission of COVID-19, and ensuring access for children with disabilities, (CEHRD, 2021, p.96)

The closure of schools and various educational institutions was repeated during the second wave of COVID 19 in 2020/2021. As a result, the Nepal Government published Secondary Education Examination (SEE) exam results based on internal assessment, second time in 2020/21. However, the grade 12 examination was conducted face to face after postponing the exam routine multiple times. The performance in internal assessment was a basis for evaluating the grades of 10th students as per the government's decision.

\section{Response to COVID-19}

\section{Nepal Government's response}

To curb the spread of the virus across the country, a High-Level Coordination Committee for the Prevention and Control of COVID-19 was formed by the government of Nepal on March 1, 2020. This became the COVID-19 Crisis Management Centre, later, it started the COVID-19 control activities imposing a nationwide lockdown and a ban on international flights and point of entries to stop the inflow of people into the nation (MOHP, 2021, p.2). The government took several steps during the pandemic including health screening mechanisms in all 43-border connecting areas (MOHP, 2021p. $x$ vi). The healthcare infrastructure was overwhelmed with a huge burden on the public health system during generalized wave in the middle of July 2021 (MOHP, 2021, p. xvii).

The MOHP trained personnel under the Epidemiology and Disease Control Division (EDCD) along with WHO field personnel were mobilized to conduct extensive contact tracing based on the flight details and movement history to identify individuals with potential infections (MOHP, 2021.p.49). The Case Investigation and Contact Tracing (CICT) teams - with the coordination of the EDCD, the district health office team, and local level authorities - in Kathmandu Valley and WHO field personnel were formed as it had the most concentrated number of cases in the country (MOHP,2021 p.55).

In April, 2020 when COVID-19 cases began to surge, reporting was started from designated hospitals, laboratories, health directorates, Provincial Health Emergency Operations Centres (PHEOCs), and the Ministry of Social Developmental (MOHP,2021, p.58). The government took several measures to strengthen the capacity of the National Public Health Laboratory (NPHL) with support of WHO through the Global Outbreak Alert and Response Network (GOARN), and later the NPHL started to formulate surge testing plans (MOHP,2021 p.61).

Recognizing that existing 25 hub hospitals across the country were not adequate, the MoHP added over 150 additional hospitals, including private service providers as designated COVID hospitals (MOHP,2021 p. xix).

After the confirmation of the country's second COVID-19 positive case, the first nationwide lockdown began on March 24, 2020. With purpose to generate evidence to address the COVID-19 burden in the country Nepal Health Research Council (NHRC) has been conducting research activities to lead a SARSCoV- 2 /COVID-19(MOHP, p. 78).

Following the formulation of various policies, guidelines, approaches, documents, 
and directives, by the federal government COVID-19 pandemic, the provincial governments developed guidelines on COVID-19 preparedness and response activities and executed various preparedness and response measures. By and large Local governments (LGs) also implemented preparedness and response activities according to the federal and provincial government mandates to develop and distribute information, education and communication (IEC) materials, and mobilized community people (MOHP, 2021, p. 81-82).

72 different institutions were allocated by the MOHP which helped for infrastructure development, human resources support, medicine and instrument purchase, capacity development, as well as to run prevention and control programmes and other miscellaneous activities. Within less than two years period, Nepal's health system has faced unprecedented challenges due to the rapidly growing COVID-19 pandemic, it has intense long-term implications for individuals, societies, and health systems across the country MOHP, 2021p. 2).

\section{Nepali army's engagement in COVID -19 care and prevention}

Nepali Army (NA) was actively involved in the COVID -19 care and prevention in Nepal from the very beginning of the COVID -19 pandemic. NA started to provide its services by importing necessary medical equipment for COVID- 19 and provided medical expertise to handle COVID-19 cases. The Government of Nepal repatriated 175 Nepali citizensmostly students - from Wuhan on February 15 , and they were quarantined and allowed to go back to their families after testing negative. (MOHP, 2021, p.3). Later the Nepal army was a member of the COVID-19 Crisis Management Centre (CCMC) formed by the Government of Nepal to carry out responses in an integrated manner through a unified group of representatives from the central, provincial, and local levels of government, as well as the security department and all other stakeholders (MOHP, 2021, p.20).

As per the government, a trained squad of the NA was involved in the management of dead bodies and in the presence of the relatives of the deceased, the team would either cremate or bury the bodies. Prior to being taken for last rites, the body would have to be disinfected and placed in a body bag. (MOHP, 2021, p. $33)$.

After the nationwide lockdown on 24th March, 2020 in India, many Nepali migrant workers began returning to Nepal. At that time, NA was involved in managing their arrival in the border areas by constructing holding area, health desks and transporting them to their hometowns. By and large the Army was involved in facilitating contact tracing of the COVID-19 infected persons and preparing quarantines at the central level and all provinces by establishing COVID-19 coordination center, and isolation wards in hospitals. Medical Supplies required to combat COVID-19 pandemic, procured by NA arrived in Kathmandu from Guangzhou, China on May 19, 2020. 18.7 tons of medical equipment was brought from China on a wide-body aircraft of Nepal Airlines. Nepal Government decided on March 29, 2020, to task Nepal Army to procure medical supplies required to combat COVID-19 through government-to-government process. Besides the wide body aircraft, NA also used the land route to bring the medical supplies (Nepal Army, News Update, 2020). On the whole, NA has played a vital role in combating the 
COVID-19 pandemic.

\section{Health diplomacy: government initiatives on COVID-19 Care and prevention}

Fauci (2007) defined global health diplomacy as "winning hearts and minds of people in poor countries by exporting medical care, expertise and personnel to help those who need it most", while Kickbusch et al. (2007) defined it as a"multi-level, multi-actor negotiation processes that shape and manage the global policy environment for health" (cited in Lee and Smith, 2011, p,1) it is further worth mentioning the definition given by Health Diplomats (2009):

"Health Diplomacy is the chosen method of interaction between stakeholders engaged in public health and politics for the purpose of representation, cooperation, resolving disputes, improving health systems, and securing the right to health for vulnerable populations." (Cited in Lee and Smith, 2011, p,1)

Global Health Diplomacy (GHD) refers to coordinating global policy solutions to improve global health in which governments and non-state actors work together. It involves multi-level process involving international stakeholders and local organizations for improving health care delivering supplies like medical equipments, expertise and human resources (Leeda,2014). In the context of combating COVID -19 pandemic we can consider the collaboration between the government and non-government sectors for fighting against the COVID -19 global based on the capacity of the country.

Nepal's health diplomacy by and large has worked out to large extent. COVID-19 vaccines have reached billions of people worldwide and by end of November Nepal has administered 18.3 million doses of covid vaccine (WHO, 2021). It has got the vaccines with support from various countries mainly from China, USA, India and Japan. Vaccine diplomacy appeared in South Asia from China and India. After China offered its vaccines to Pakistan, Sri Lanka, Nepal and Bangladesh, consequently, India also adopted its vaccine diplomacy in the neighborhood (The Kathmandu Post, November 18, 2021).

Vaccines produced in China and India are much cheaper and accessible. The government of Nepal took proactive initiatives to get Covid-19 vaccines like the COVAX based on the affordability as it had no capacity to purchases vaccines produced in the western world.

Earlier this year, Nepal followed diplomacy measures for obtaining support from India. Nepal's foreign minister as well as the Minster for Health and Population Education took various diplomatic measures. Nepal's health diplomacy was therefore focused on getting support for medical equipments and vaccines from its neighboring countries and other countries through diplomatic relations with US, UK, Germany, Japan and France.

\section{WHO support}

WHO have been providing various types of support to Nepal to combat with COVID -19 pandemic. WHO issues weekly epidemiological and operational updates. WHO also provides crucial advice to the people, publishes situational reports, technical guidelines, travel advice and shares update on the contribution of various countries to $\mathrm{WHO}$ for COVID -19 prevention and treatment. Besides, WHO has also issued the COVID-19 Strategic Preparedness and Response Plan (SPRP) for 2021. With SPRP, measures 
are taken at national, regional, and global levels to overcome the ongoing challenges in the response to COVID-19.WHO has also recommended self-isolation until recovery if someone developed symptoms or tested positive for COVID-19 (WHO, 2021).

\section{World Bank support}

With focus on the immediate response and preparedness to fight the virus, the World Bank approved a fast-track \$29 million COVID-19 Emergency Response and Health Systems Preparedness Project to help Nepal (The world Bank Press Release, April 7, 2020)

\section{China}

China and Nepal have been firmly standing together and helping each other towards pandemic prevention and control responses. China at its most difficult time in the fight against the virus made commitment for continued support for Nepal's efforts against the pandemic as stressed by the Chinese president and Nepali president during the telephone conversation (CIDA, 2020). China began its support by handing over the Chinese medical supplies on May 11. China is the largest vaccine donating country to Nepal. China started to support Nepal by providing 1 million doses of a COVID-19 vaccine. (Reuters, May 26, 2021).

\section{The United States of America}

The United States of America has also provided support to Nepal in the form of emergency funding to combat the disease and to support the Nepali people in US Embassy Nepal (2021). US has provided vaccines to Nepal after persuasion of the Embassy of Nepal in Washington, D.C. (USAID Nepal, 2021)
Nepalese Ambassador to USA held a virtual meeting among the representatives of Nepali community organizations in the United States to discuss on COVID-19 relief efforts On May 23,2021 , to cope with the second wave of the COVID-19 pandemic, The USA has provided assistance of 1,534,850 doses of COVID-19 vaccines to Nepal through COVAX. (Relief web, 13 July, 2021)

\section{Indian government}

As part of the bilateral cooperation to fight the coronavirus pandemic, India provided medical supplies, including testing kits to Nepal (The Hindu, 2020). India provided doses of the Covishield vaccine, developed by the University of Oxford and AstraZeneca and manufactured by India's Serum Institute in grants to Nepal in the beginning of 2021. (ORF, 2021).

\section{Bhutanese government}

Nepal received 230,000 doses of AstraZeneca vaccine from the Bhutanese government (The Kathmandu Post, August 6, 2021)

\section{UK Government}

In April, 2021 the United Kingdom provided $£ 802,000$ grant to Nepal as per its early commitment to tackle the unprecedented challenges to strengthen Nepal's response to COVID-19 (Republica, April 12, 2021). It was reported that this support contributed inmobilizing the World Health Organization (WHO) to focus on increasing Nepal's technical expertise and strengthening sample and laboratory management; disease surveillance and contact tracing. Additionally, it helped in improving infection prevention and control and; strengthening information management; and improving the clinical management of cases (Republica, April 12, 2021). 


\section{Japan government}

To cope with the second wave of the COVID-19 pandemic, the Government of Japan under the Japanese Grant Aid provided medical equipments like 25 Portable Ultrasound Image Diagnostic Systems to 25 hospitals in Nepal, 23 of which were already handed over on 16th May (Embassy of Japan in Nepal, Press Release, May 18, 2021).

\section{Germany}

As part of bigger European effort and ongoing cooperation between Germany and Nepal, to contain its rapid surge in COVID-19 infections, Germany provided 112 ventilators, 2,068,500 K95 masks, 29,000 pulse oximeters, $34,030,000$ surgical masks, 5 isolation center tents, 400 gum boots, 25,000 liter hand disinfectants and others items to address the need rapid surge in COVID-19 infections (German Embassy, Press Release, Press Release, June 8, 2021).

\section{French Government}

In response to the Government of Nepal's call for support, the French Government (French Ministry of Foreign Affairs/Crisis and Support Centre) provided 7-ton relief equipment consisting of masks, antigen test kits, respirators/ventilators and protection glasses. (Embassy of France in Nepal, 2021)

\section{Overall Impact at National Level and Suggestions}

Due to restrictions in international travel, the tourism receipts in Nepal was projected to decline by 60 percent in 2020 resulting in a loss of foreign currency earnings worth US $\$ 400$ million. On the whole, the GDP growth rate of 8.5 percent plunged below 2.5 percent in 2019-2020. Due to loss of alternative source of income, especially the women, from lower income groups were greatly affected (IIDS, 2020, p.14))

As revealed by the survey results, 28 percent of men lost their jobs during the lockdown, compared to 41 percent of women (IIDS, 2020, p.14). On the whole, it was apparent that the COVID-19 pandemic will affect Nepal's long-term development goals of graduating from the status of Least Developed Country in 2021, meeting the Sustainable Development Goals (SDGs) and becoming a middle-income nation by 2030. The assessment revealed that due to COVID-19 pandemic, the most vulnerable people who earn their livelihood from agriculture and natural resources would be affected. Nepal being highly vulnerable to climate change risks, the impacts of COVID-19pandemic combined with those of climate change will hit the most vulnerable people, particularly those who draw their livelihood from climate sensitive sector such as agriculture and natural resources (IIDS, 2020, p.15))

Based on the assessment three recommendations were made to combat the negative social and economic impacts of the COVID-19 pandemic in Nepal.

- Protecting the vulnerabilities brought by climate change for strengthening social protection, building climate resilient infrastructure and sustaining livelihoods.

- Augmenting human capabilities based on Nepal's pattern of public finances to safeguard development gains and build economic resilience.

- Reversing monetary policy options for boosting agri-businesses, creating green productive assets by lowering economy-wide rates of lending, injecting liquidity into the banking sector (IIDS, 2020, p.15). 
Based on the lesson learnt, ensuring a better health infrastructure and improving the quality of health services, and developing a strong public health system at large remained to a priority of the government (MOHP, 2021, p.xvi).

Therefore, the government should endeavor to bring relief measures by creating jobs for the migrant workers within country and also it must strengthen its diplomatic efforts for providing vaccines to its entire population and the government must also be fully prepared for unexpected disasters in future. In the education sector the government must develop the capacity for running the alternative learning model to cope with COVID-19 pandemic.

\section{Recommendations:}

- Health preparedness is necessary to successfully deal with unprecedented conditions like this current pandemic.

- This should be taken as an opportunity to create more inclusive and universal health plans and policies.

- Attention should be given to vulnerable groups like women, elderly, people with disabilities etc while planning.

- Proper implementation and monitoring of policies should be done to ensure that the vulnerable groups feel included and respected.

The limited number of resources in Nepal as compared to that of developed nations is a challenging factor for COVID-19 management. However, NA can focus more on educating LGs and members of civic society about the lesson learnt and help them take measures in preparation of proper quarantine and isolation setup and mobilize its trained human resources for running educational awareness campaigns and help reduce the stigma and discrimination.

\section{References}

Amul, G. G. (2021). Chapter 21: Revitalising Global Health Governance. Non-Traditional Security in the Asia-Pacific, 125-128.

CEHRD. (2020). COVID-19, Education Cluster Contingency Plan, 2020, Nepal Education Cluster. Sanothimi Bhaktapur: CEHRD.

CEHRD. (2020). Status Report 2019/2020. Sanothimi Bhaktapur: CEHRD.

CEHRD. (2020). Annual Strategic Implementation Plan (ASIP) \& Annual Work Plan \& Budget (AWPB) FY 2020 . Sanothimi Bhaktapur

CEHRD. (2021). Annual Strategic Implementation Plan (ASIP) \& Annual Work Plan \& Budget (AWPB) FY 2021 . Sanothimi Bhaktapur

CIDCA. (2020, 6 11). China donates medical supplies to Nepal to help fight COVID-19. Retrieved from CIDCA(2020). China donates medical supplies to Nepalhttp://en.cidca.gov. cn/2020-05/11/c_489546.html

Dawadi, S., Giri, R., \& Simkhada, P. (2020). Impact of COVID-19 on the Education Sector in Nepal - Challenges and Coping Strategies.

Embassy of France in Nepal. (2021, 6 2). Press Release. Embassy of France Retrieved from https://np.ambafrance.org/Press-releaseFrance-s-support-to-Nepal-in-its-fightagainst-Covid-19

Embassy of Japan in Nepal. (2021, 5 18). Press Release, Embassy of Japan. Retrieved from https://www.np.emb-japan.go.jp/itpr ja/11_000001_00488.html

Ewing, J. J., \& Anthony, M. C. (2021). Assessing the Emergence of Non-Traditional Security 
Studies. Non-Traditional Security in the Asia-Pacific, 3-9. Retrieved from https://doi. org/10.1142/978981122443

German Embassy Kathmandu. (2021, 6 8). Press Release. Retrieved from https://kathmandu. diplo.de/np-en/aktuelles/-/2464798

IIDS. (2020). Rapid Assessment of SocioEconomic Impact of Covid-19 in Nepal. Retrieved from https://www.undp.org/pressreleases/nepal-multiple-sectors-economicgrowth-slammed-pandemic-and-lockdownstudy-finds

ILO. (2020). Impact of COVID-19 on Nepali Migrant Workers: Protecting Nepali Migrant Workers during the Health and Economic Crisis, Challenges and the Way Forward. Retrieved from https://www.ilo.org/wcmsp5/ groups/public/---asia/---ro-bangkok/--ilo-kathmandu/documents/briefingnote/ wcms_748917.pdf

K.C, T. (2020). Impact of COVID-19 on university education, NEPAL: review paper. Tribhuvan University Journal, 35(2), 34-46. doi:K.C., Tulza( 2020) . Impact of COVID-19 on university education, NEPAL: review paper, https://doi.org/10.3126/tuj.v35i2.36

Lee, K., \& Smith, R. (2011). What is 'Global Health Diplomacy? A Conceptual Review. Retrieved from Article in Global Health Governance: https://www.researchgate.net/ publication $/ 261833347$

Ministry of Health and Population Education (MOHP). (2021). Responding to COVID-19 Health sector preparedness, response and lessons learnt. doi:https://mohp.gov.np/ attachments/article/703/Responding $\% 20$ to $\% 20$ COVID-19,\%20Health $\% 20$ sector $\% 20$ preparedness, $\% 20$ response

Nepal Army. (2020, 5 19). News Update. Retrieved from https://www.nepalarmy.mil. np/viewnews/436, May 19, 2020

NTS-Asia. (2021, 10 10). About Non-Traditional Security . Retrieved from https://rsis-ntsasia. org/about-nts-asia/

Ong, S. (2021). Chapter 20: Towards a More Comprehensive Global Health Agenda. NonTraditional Security in the Asia-Pacific, 119124.

ORF. (2021). Health express. Retrieved from https://yukon.ca/en/news/february-18-2021covid-19-update

Pant, S., \& Subedi, M. (2020). Impact of COVID-19 on the elderly. Journal of Patan Academy of Health Sciences, 32-38.

Pant, S., Koirala, S., \& Subedi, M. (2021). Access to Maternal Health Services during COVID-19. Europasian Journal of Medical Sciences, 1-5.

Pant, S., Koirala, S., \& Subedi, M. (2021). Impact of COVID-19 on People with Disabilities. Europasian Journal of Medical Sciences, 1-5.

Relief Web. (2021, 7 13). Relief Web( 2021), Press Release on vaccine support from the US. Retrieved from Relief Web( 2021), Press Release on vaccine support from the US, $13 \mathrm{https}: / /$ reliefweb.int/report/nepal/pressrelease-vaccine-support-us

Republica The English Daily . (2020, 4 12). Uk Provides Grant to Help Strengthen Nepal's Response to COVID-19. Republica. https:// myrepublica.nagariknetwork.com/news/ukprovides-ps802-000-grant-to-help-strengthennepal-s-response-to-covid-19/

Reuters. (2021, 5 26). China to gift 1 million COVID-19 vaccine doses to Nepal. Reuters. https://www.reuters.com/business/healthcarepharmaceuticals/china-gift-1-million-covid19-vaccine-doses-nepal-2021-05-26/ 
Rising Nepal (2021, May 11). COVID-19 And The Threat Of Cybercrime. The Rising Nepal. https://risingnepaldaily.com/opinion/covid19-and-the-threat-of-cybercrime

Saha, S., \& Chakrabarti, S. (2021). The Nontraditional Security Threat of COVID-19 in South Asia: An Analysis of the Indian and Chinese Leverage in Health Diplomacy. South Asian Survey, 28(I), 111-132. doi:https://journals.sagepub.com/doi/ pdf/10.1177/0971523121998027

Singh, D. B., \& Sahi, D. K. (2021). Assessment of the impact of COVID-19 on transportation and its inter-linked sectors of Nepal. Journal of Engineering Issues and Solutions, 1(1), 8-19. Retrieved from https://www.nepjol.info/ index.php/joeis/article/view/36813/28653

Smith, A. W. (2021). COVID-19 in comparison with other emerging viral diseases: risk of geographic spread via travel. Tropical Diseases, Travel Medicine and Vaccines.

Srikanth, D. (2014). Non-traditional security threats in the 21st century: a review. International Journal of Development and Conflict, 4.

The Hindu. (2021, 5 17). Nepal thanks India for providing medical supplies to fight COVID-19. Retrieved from The Hindu ( 2020) Nepal thanks India for providing medical supplies to fight COVID-19, Updated May 17, 202https:// www.thehindu.com/news/international/nepalthanks-india-for-providing-medical-suppliesto-fight-covid-19/article31606721.ece

The Kathmandu Post. (2021, 10 3). Bhutan delivers 230,000 doses of Covid-19 vaccine to Nepal. The Kathmandu Post. Retrieved from https://tkpo.st/37oGiag

The Kathmandu Post. (2021, 1 11). Vaccine diplomacy and Nepal. Retrieved from https:// kathmandupost.com/columns/2021/01/11/ vaccine-diplomacy-and-nepal

USAID Nepal. (2021, 4 30). Press Release. Retrieved from USAID Kathmandu( 2021), Press Release, Aprihttps://www.usaid.gov/ nepal/press-releases/apr-30-2021-unitedstates-provides-additional-funding-supportnepal-second-wave-covid-19

Valenza, D. (2020, 3 20). The Irresistible Rise of Health Diplomacy: Why Narratives Matter in the Time of COVID-19. Retrieved from https:// cris.unu.edu/health-diplomacy-narratives

WHO. (2021). Advice for the public: Coronavirus disease (COVID-19). Retrieved from https:/www.who.int/emergencies/ diseases/novel-coronavirus - 2019/ advice-for-public? gclid=Cj0KCQjwt6LBhDlARIsAIPRQcLnQx-4J0xaYfOWo9 lamUobajehkX7Q4bhgjbws7tZ-7AYSTmrdHUaAuZ1EALw_wcB,

WHO. (2021, 12 5). Global > Nepal. Retrieved from World Health Organization: https:// covid19.who.int/region/searo/country/np

WHO. (2021, 10 31). Situation Update \#80Corona virus Disease 2019 (COVID-19), WHO Country Office for Nepal. Retrieved from https://reliefweb.int/report/nepal/ situation-update-80-coronavirus-disease2019-covid-19-who-country-office-

World Bank. (2020, 4 3). Press Release, April 7. Retrieved fromhttps://www.worldbank. org/en/news/press-release/2020/04/03/worldbank-fast-tracks-29-million-for-nepal-covid19-coronavirus-response 